\section{THE CERAMIC INDUSTRIES. ${ }^{1}$}

THE intimate relation between the various industries and clay is seldom appreciated. The gas industries, coking plants, iron, steel, and non-ferrous metallurgy; glass manufacture; and the ceramic industries are all to a large extent dependent on good refractory materials. It is therefore obvious that a manufacturing country must devote much attention to its clays, for progress in these industries is largely dependent on improved refractories. In the pre-war days, consumers were pushing the firebrick manufacturers for improved methods of manufacture to meet the more severe fire-tests imposed by modern conditions. It was the custom to vaunt the German methods of manufacture, and to condemn the benighted British. There is much truth in the old firebrick manufacturer's contention that God has given each manufacturer particular clay-beds, and that no improvements in methods of manufacture will make a bad clay into a good one. As a matter of fact, there appears as much difference in the character of clays from different beds as there is between different individuals; and to get each clay to do its work most efficiently it must be humoured in manufacture and in use. If the firebrick be not in a suitable environment, it will break down. Experience is constantly bringing to light cases where good firebricks do satisfactory work in one furnace, and fail in another, where, at first sight, the conditions appear similar, thus showing that firebricks are sometimes very sensitive to local conditions.

Satisfactory progress can be made only by the co-operation of maker and user. The experience of both must be pooled for the common good. We can then find what clays are best adapted for particular purposes, and the manufacturer will have a more clear and definite idea in what directions he can best modify his methods to make his clays do their best work. This gigantic task has been undertaken from the point of view of the gas engineers under the energetic lead of $\mathrm{Mr}$. S. J. Bywater, and slow progress has been made in certain directions. To hasten the final victory, the Geological Survey can help very materially. We want to know the specific character of the different clay beds in the country, and a host of other questions which can best be answered on the geological side. There have been a score of elaborate reports on the clay deposits of different parts of the United States, and half-adozen likewise for Canada. Several of these have the character of pot-boilers, and cannot be of much practical use; a few photographs of claybanks, a few diagrams from the machinery catalogues, and a few clay analyses do not fulfil the required purpose. In England we have lagged far behind even this. We therefore welcome with

1 (I) "A Handbook to the Collection of Krolin, China Clay, and China Stone in the Museum of Practical Geology." By J. Allen Howe, Curator. With an appendix by Allan B. Dick. (London, rgr4.),

(2) "A Study of the Atterberg Plasticity Method." Bv C. S. Kinnison. No. 45. Technological Papers of the Bureau of Standards. (Washington, rgr 5.) of Quebec." By J. Keele. Memoir 54 of the Canada Genlogical Survey. (Ottawa, 1915.)

No. 24 IO, VOL. 96] pleasure the appearance of the work on "China Clay and Cornish Stone" by Mr. J. Allen Howe, curator of the Jermyn Street Museum (I). Is it too much to hope that this work is the forerunner of a series dealing with the whole of the different types of clay in our country? This particular memoir is of most use to the pottery industry, since the materials here discussed have some special qualities which are not required from fire clays per se, and which give the china clays a special commercial value. The mere fact that the pamphlet has appeared is a hopeful sign. It has long been the plaint of the clay industries that a great deal of public money has been spent year by year to publish a pile of Memoirs of the Geological Survey of the United Kingdom. Of course, pure geology is exceedingly important and necessary, but why the applications should have been virtually neglected is not always clear.

In the introduction to his brochure, $\mathrm{Mr}$. Howe makes a contribution towards rectifying the general muddle as to the precise meaning of the terms "china clay" and "kaolin"; he then gives a general description of the methods of extracting china clay practised in the south-west of England; then follows a general sketch of the distribution of china clay in various parts of the world. There are also discussions on Cornish or China stone; on the uses of these materials; and on the origin of china clay. There is a review of some recent work on the nature of kaolinite and related minerals. This is followed by a collection of analyses, physical tests, statistics, and a bibliography. Mr. Allan B. Dick contributes an exceptionally valuable appendix on the identification of transparent mineral grains under the microscope.

There are some very useful and trustworthy data in the chapter on analyses and physical tests. These are mixed with a lot of old and inaccurate work which possibly might have been omitted without the loss being felt. Perhaps, however, there is something in the argument that bad data are better than no data at all. The table of exportation of china clay to foreign countries recalls a scandalous anomaly. We know that before the war several factories on the Continent were purchasing English china clay delivered on the works at a lower price than that paid by the Staffordshire potters. It appears that in I9I3 Germany purchased more than 70,000 tons at about $f_{1} 80,000$; this is interesting in view of the investigations recently made at Charlottenburg with the patriotic object of displacing English china clays by German clays in Deutschland.

In "A Study of Atterberg's Method of Measuring Plasticity" (2) Mr. C. S. Kinnison compares the results made by Atterberg's method with those based on wet to dry contraction of clays, and on the water of plasticity method. The results are not very promising. This is not surprising. In my opinion, plasticity is a mechanical property, the magnitude of which is primarily estimated by the potter's thumb, and unless the proposed methods measure approximately the same mechanical property they do not measure plasticity at all, but rather some other quality of clay. 
The report by Mr. Keele on the clays of Quebec (3) shows that Canada recognises the importance of a definite knowledge of its clay resources. In the preface Mr. Keele says: "Chemical analyses are of little value to him (i.e., the clay-worker), as practically no information regarding the behaviour of clays can be derived from such analyses." This might be true if the statement refers to some clayworkers; but it does not require a Gaboriau's Lecoq to deduce a very great deal of important practical information from the analysis of a clay, information, too, which could be otherwise gleaned only after painful processes of trial and failure. The methods of collecting the so-called practical data are largely those followed in the preparation of numerous other reports published further south. This is good so far as it goes, but we must remember that some of the best of these reports were pioneers in this department of clay literature, and have served a very useful purpose. There are many important properties of clays which the progressive worker ought to know which might advantageously have been included. New knowledge, new requirements. Of course, Mr. Keele's report is mainly of local interest, and without a knowledge of the particular district covered by the memoir it can be said that the present report compares very favourably with the best of those made for other localities.

\section{J. W. Mellor.}

SCIENTIFIC STUDIES OF STINE FEVER. ${ }^{1}$ THE committee appointed by the Board of 1 Agriculture and Fisheries to inquire into swine fever has issued its final report, which contains conclusions of far-reaching importance, and since the main conclusions are based on the results of experimental investigation carried out on the recommendation of the committee by one of its members, Sir Stewart Stockman, who is also the Chief Veterinary Officer of the Board, the report would appear to portend an early radical change in the campaign against the disease.

The causal agent of swine fever is a living organism which is beyond the range of microscopic visibility, and will pass, with fluid containing it, through the pores of the finest bacterial filter. No method of cultivating it artificially has yet been discovered.

Amongst its conclusions, the committee makes the following statements:- That the manure of pigs suffering from swine fever is infective, and that a period of fourteen days may be regarded as sufficient to bring about the disinfection of infective manure through natural causes; (one member of the committee, however, Prof. Penberthy, considers that the experiments on which the latter view is based are not conclusive, and that further experimentation on the point should be undertaken before being accepted as a basis

1 Final Report of the Departmental Committee appointed by the Board of Agriculture and Fisheries to inquire into Swine Fever. Part iv. Final Report, Minutes of Evidence and Appendix. Cd. 8045. Price $8 d$. Can be obtained direct from Messrs. Wyman and Sons or through any bookseller. NO. $24 \mathrm{IO}$, VOL. 96$]$ for administrative measures); that rats are not, as has been suggested, pathological carriers of swine fever, and that all the available evidence suggests that swine fever is not disseminated by external parasites, such as lice and fleas; that while persons, vehicles, and animals may carry infective material mechanically, the evidence leads to the conclusion that all wide dissemination of the disease is due to the movement of infective pigs; that a pig may become infective in three days after contracting infection, and before it has actually exhibited clinical symptoms of the disease, and may remain infective for a considerable period, the extent of which has not been fully ascertained; and that there would appear to be cases in which healthy pigs, which have not been visibly affected by swine fever and on postmortem examination show no evidence of having suffered from swine fever, yet are infective, and continue to be so for a considerable time.

On the question of serum treatment and vaccination as methods of combating swine fever, the committee reports that the serum of a hyperimmune pig, if injected into other pigs, will pro. tect them for a short time against swine fever if they are free from infection at the time of treatment, but it is disappointing in the case of young sucking pigs. It has no curative effect. This short period of immunity can be converted into a prolonged immunity if the pigs treated with serum are allowed to come into contact with infection, i.e., by what may be termed "natural vaccination." "Artificial vaccination" may also be carried out. It consists of the simultaneous application of serum injection with an infection produced by the administration of virus by feeding or by inoculation, but the process is attended by greater risks of producing severe forms of swine fever than "natural vaccination."

The committee is of opinion that the continual prevalence of swine fever appears to be due principally to its highly contagious character and the difficulty of its recognition by the pig owner in its early stages and in its milder forms; and the members consider that the extirpation of the disease is practicable only by such drastic measures of slaughter as would involve a prohibitive outlay, and by such severe restrictions on movement as would be fatal to the industry of pig-keeping. New preventive methods, however, may bring about a condition more favourable to the prospect of eradicating the disease.

Recommendations. - In view of all the evidence laid before them, the committee recommends that the attempt to extirpate the disease by general slaughter should be abandoned for the present, and that the immediate object of future policy should be to reduce the mortality from the disease by the use of protective serum as soon as possible in infected herds. The production of immune herds by "artificial vaccination" should be undertaken under suitable conditions. To control the spread of the disease, isolation of infected premises should be maintained, but restrictions 